\title{
Testamento y codicilo de Eugenio de Salazar
}

El 17 de octubre de 1602 - -según reza la portada del expediente manuscrito dondę aparecen el testamento y el codicilo del poeta novohispano Eugenio de Salazar (1530-1602)—, ambos pliegos autógrafos fueron abiertos ante un notario público, a instancias de la viuda de este personaje de nuestras letras, a la que se entregó una copia fragmentaria del documento principal: "Este día se dió traslado a doña Catalina Carrillo de la cláusula honze del testamento, con la caueza y pie que fue ynstituiçión de herederos y albaçeas".

Con los datos incluidos en diversas fuentes documentales, tenemos noticias sobre cómo un día antes había ocurrido el fallecimiento de Salazar, cuya obra en verso aún se halla inédita en su mayor parte.

Al momento de morir el 16 de octubre de 1602, el escritor tenía 72 años de edad. Nacido en la ciudad de Madrid alrededor de 1530 (Schäfer 1: 356), era a la sazón miembro del Real Consejo de Indias, honroso empleo que ya casi al final de su vida lo había llevado de regreso al suclo patrio desde su asiento en la Nueva España. Con este último cargo otorgado por los Austrias. el magistrado logró coronar exilosamente la dilatada carrera burocrática en el Nuevo Mundo, donde entre otros puestos llegó a desempeñar los oficios de oidor y fiscal en las audiencias de Santo Domingo, Guatemala y México.

La orden que con esa fecha fue promovida para abrir los papeles personales que asientan in scriptis la última voluntad del autor de la Navegación del alma --poema que en breve editaré en la UNAM--, está respaldada por el alcalde Marín Fernández 
Puertocarrero, bajo la certificación del notario Bartolomé Gallo, escribano público que a su vez también estuvo encargado de la legalización correspondiente de la testamentaría.

Firmado conjuntamente por la pareja de esposos viajeros, el primero de los documentos que publico en esta ocasión ofrece un verdadero arsenal informativo, el cual ayudará a cubrir algunas de las lagunas bio-bibliográficas que todavía subsisten sobre la trayectoria de Eugenio de Salazar, vecino de la ciudad de México durante las dos últimas décadas del siglo xvı. Con talęs noticias, por ejemplo, queda sin duda desechada la apostilla "y Alarcón" que, como segundo apellido, venía siendo adjudicada a nuestro escritor, al considerársele erróneamente como hijo del capitán Pedro de Salazar y de doña María de Alarcón (EUIEA). A través de las líneas preliminares del testamento autógrafo, firmado justamente un año antes de su muerte, el propio autor revela que sus padres fueron en realidad don Pedro de Salazar y su mujer legítima doña Aldonça Vásquez de Carrión, vecinos ambos de la villa de Madrid.

Por otro lado, el protocolo notarial proporciona datos precisos sobre la familia que en la vida real formaron "Eugonio", y "Carilia", la pastoril pareja de amantes idealizada poéticamente en los versos autobiográficos de la Silva de poesía, el cancionero aún inédito de nuestro autor.

La temprana muerte de los dos hijos varones de Eugenio de Salazar y Catalina Carrillo - Pedro y Fernando de Salazar Carrillo- , queda referida directamente en una de las cláusulas testamentarias, si bien no se aclara si ocurrió en América. En esc párrafo, ambos consortes declaran estar "sin succesión. legítima y forçosa" y deciden instituirse mutuamente en "herederos universales" de todos sus bienes. Con tal acuerdo, la muerte de uno de los donantes imponía al sobreviviente la consigna de suceder y heredar al que hubiese fallecido en primer término. El testamen10 se halla limado en Madrid, con fecha del $1^{\circ}$ de mayo de 160I, ante el notario público Pedro Duarte; el codicilo, en cambio, carcce de autorización legal y aparece suscrito en Valladolid, el $1^{\circ}$ de diciembre de ese mismo año.

El legajo en que se encuentran depositados estos dos precio- 
sos documentos reúne también los papeles protocolarios incoados por algunas autoridades civiles para proteger los derechos legales de doña Eugenia de Salazar, nieta del poeta. Homónima de Salazar, la menor no debe confundirse con una supuesta hija de éste, también del mismo nombre, que nació en las Islas Canarias y murio al parecer de corta edad. Hija natural de Femando de Salazar Carrillo y de Ysauel de Monrroy, la nieta tenía únicamente cinco o seis años de edad, según se podía apreciar por su "aspecto" y "figura". Por ello, a instancias del licenciado Francisco Velorado Buitrón —uno de los albaceas testamentariosla niña recibe como abogado defensor al procurador Bartolomé Martínez, quien sucesivamente figura en esos autos como su representante legal. .

Los dos papeles autógrafos que hoy tengo la oportunidad de dar a conocer, se custodian en la capital española a unos pasos del Museo del Prado, dentro del rico acervo documental del Archivo de Protocolos de Madrid (Protocolo 2,695, Bartolomé Gallo, fols. 457r-476v).

Humberto Maldonado Macías Instituto de Investigaciones Filológicas, UNAM

\section{Documento 1 \\ Testamento}

En el nombre de Dios padre y hijo y spíritu sancto, tres personas y vn solo Dios verdadero, en quien (por su piedad) firmemente creemos, y a quien adoramos, y de la gloriosa Virgen María Nuestra Señora: el doctor Eugenio de Salazar, del Consejo de Indias de Su Magestad, hijo legítimo de Pedro de Salazar y de Aldonça Vásquez de Carrión, ${ }^{1}$

${ }^{1}$ El cronista Pedro de Salazar, historiador de Carlos V, llegó a tener el grado militar de capitán y escribió varios libros, publicados antes de su muerte, ocurrida en 1576. El testamento lo confirma como autor de un libro inédito de "nouelas" o "quentos", que fue localizado por José Manuel Blecua Pardiñas (Blecua Pardiñas 92-93). 
su legítima muger, mis señores padres defunctos que Dios aya, vezinos que fueron de la villa de Madrid, ${ }^{2}$ y doña Catalina Carrillo, ${ }^{3}$ muger del dicho doctor Eugenio de Salazar, hija legítima de Fernán Carrillo de Ribera y de María de Paz, su muger, mis señores padres, ${ }^{4}$ vezinos que también fueron de la dicha villa, dezimos que hazemos y ordenamos juntamente nuestro testamento y v́ltima voluntad en la forma y manera siguiente.

$1^{\circ}$. Primeramente confesamos y afirmamos que creemos y tenemos todo aquello que nuestra madre la Sancta Iglesia de Roma tiene, cree y enseña, y protestamos viuir y morir en esta fe cathólica y supplicamos a nuestro señor Iesuchristo nos dé firme constancia en ella parạ que no le offendamos y nuestras ánimas salgan en el estado que al seruicio suyo y a nuestra saluación conuenga, las quales y nuestros cuerpos mandamos a la diuina Magestad que nos crió y hizo de nada. $2^{\circ}$. Pedimos que nuestros cuerpos sean sepultados, el de mí el dicho Eugenio de Salazar, en el hábito del señor San Francisco, y el de mí İa dicha doña Catalina Carrillo, en el del señor Sant Augustín, y que el que primero de nos muriere sea sepultado en la iglesia parrochial o monasterio que estuuiere más cerca de nuestra posada, donde pedimos por charidad a los padres, cura y beneficiados o prelado y religiosos nos manden dar sepultura, pagando nuestros albaceas la limosna que sea justa, y que el que de nos después muriere, sea enterrado en la misma sepultura, si muriere en el mismo pueblo, y que sobre ella se ponga vna losa de piedra blanca con vnas letras sculpidas que manifiesten nuestros nombres y como marido y muger estamos allí sepultados. Lo qual se entienda si muriéremos fuera de la villa de Madrid, porque muriendo en ella queremos ser sepultados en la iglesia del señor San Ginés, ${ }^{5}$ donde hemos sido parrochianos y donde lo fueron

${ }^{2}$ La villa de Madrid, en el paso del siglo xvi al xviI, contaba aproximadamente con una población total de 60 a 65,000 habitantes, sin considerar a los transeúntes (Domínguez Oriz 31; Carbajo Isla 134-138).

${ }^{3}$ Al margen de uno de los sonetos autobiográficos incluidos por nuestro autor en su Silva de poesía (fol. 137r), aparece el registro de cómo, con fecha del 6 de abril de 1559, el poeta casó con doña Catalina en la ciudad de Toledo. La pareja formada por "Carilia" y "Eugonio" duró 43 años.

${ }^{4}$ Al exaltar el linaje de su esposa en los versos del poema intitulado "La perpetuación de Mayo", Eugenio de Salazar dice: "Dama mora, infiel, ni luterana, / no se verá con mi beldad ufana [...]. // Bendito sea aquel varón dichoso / que el cielo destinó para consorte / tuyo [...]" (Silva, fols. 156r180r).

${ }^{5}$ La iglesia de San Ginés aún se conserva. Está en un céntrico barrio de Madrid, ubicada en la intersección que forman las calles de Bordadoras y 
los padres de mí, el dicho Eugenio de Salazar, y están enterrados, y para nuestro entierro se pida en la capilla mayor de la dicha iglesia sepultura, por la qual se dé vna limosna y se ponga sobre ella la losa que arriua está dicha con las letras referidas.

$3^{\circ}$. Los niños de la doctrina pedimos que vayán con nuestros cuerpos rogando a Dios por nuestras ánimas, y se les dé la limosna que a nuestros albaceas parezca.

$4^{\circ}$. Lo que toca a la cera y misas y lo demás de nuestro entierro y honras y otros sufragios, lo remitimos a la voluntad y disposición de nuestros albaceas, encargándoles que todo ello se mida y modere conforme al posible ${ }^{6}$ qué dexaremos.

$5^{\circ}$. A cada vna de las mandas forçosas mandamos ocho reales. ${ }^{7}$

$6^{\circ}$. Y porque podría ser que fuéssemos a cargo a algunas personas que no sabemos (o no nos acordamos) alguna cosa, y de la misma manera lo pudieron ser nuestros padres a otras personas, ordenamos que de nuestros bienes se den cient ducados ${ }^{8}$ de limosna por las ánimas de las dichas personas a dos hospitales, los más nescesitados que a nuestros albaceas parezcan, tanto al vno como al otro que sean de los que huuiere en el pueblo donde el primero de nosotros muriere.

$7^{\circ}$. Iten, yo, el dicho Eugenio de Salazar, digo que he tenido días ha voluntad de instituir vna memoria perpetua de misas en la dicha iglesia del señor San Ginés, donde como dicho es fueron parrochianos y están sepultados mis padres, lo qual por la bondad de Dios dexo concluido, y por el cura y beneficiados de la dicha iglesia aceptado de-

del Arenal, muy cerca de la Puerta del Sol. Entre los documentos custodiados en el Archivo Parroquial de San Ginés, el libro 13 de Bautismos comprende los años 1599-1603. Existen informes sobre el poder otorgado por don Pedro de Salazar, vecino de Madrid y estante en Sevilla, a favor de su hijo el licenciado Eugenio de Salazar. Con ese documento, fechado el 19 de agosto de 1567, el poeta pudo tomar en censo 500 ducados sobre las casas de la parroquia de San Ginés de Madrid, en las cuales su padre tenía parte. El protocolo está firmado por el notario público Pedro de Torres, escribano de Su Majestad (APM, Pedro de Torres, año 1567, fol. 308 apud Pérez Pastor 470; Carbajo Isla 378-379).

6 Posible: "Usado como substantivo, se toma por los bienes, rentas o medios que alguno posee o goza" (Aut.).

${ }^{7}$ El real de oro equivalía a la octava parte del peso y tenía un valor de 34 maravedíes, el equivalente a 0.91 pesetas oro modernas (Hamilion 86). Ocho reales completaban en este caso un peso oro, esto es, 2.93 pesos mexicanos modernos, en las primeras décadas del siglo xx (Benítez 89-97).

${ }^{8}$ Todavía en 1929 el ducado equivalía a 2.25 pesos mexicanos modernos (Benítez 93). 
baxo de cierto censo perpetuo 9 que les destiné para limosna de las dichas misas, el qual censo han de pagar Matheo Rodríguez de Alcántara, vezino de Madrid, ${ }^{10}$ y Diego de Alcántara, su hijo, y los demás succesores suyos perpetuamente, en razón de ciertas tierras y censos míos que yo les traspasé, la qual institución reciba Dios por su piedad para sufragio de las almas mía y de la dicha mi muger y hijos y de las demás personas en la dicha institución referidas.

$8^{\circ}$. Iten, declaro yo, el dicho Eugenio de Salazar, que de la dote que se me prometió con la dicha doña Catalina Carrillo, mi muy amada muger, assí por mi señora María de Paz, su madre, como por Alonso Carrillo, su hermano defuncto, que renunció en ella sus legítimas, ${ }^{11}$ pasaron las escrituras por ante Gabriel Hernández, escribano público del número de la villa de Madrid, y la escritura de la paga y recepción de dote pasó por ante Hernando de Medina, escribano assímismo del número de la dicha villa; mando se saquen las dichas escrituras de los registros de los dichos escribanos, y porque yo he gastado y consumido toda la dicha dote, se dé y pague a la dicha mi muger en los bienes que ella escogiere, de los que de nuestro matrimonio quedaren, todo el valor de la dicha su dote, que es todo lo que en la dicha escritura de promisión se me prometió, y más se le den las $\operatorname{arras}^{12}$ que yo la prometí, que constarán por la dicha escritura.

$9^{\circ}$. Iten, yo, el dicho doctor Eugenio de Salazar, digo que para la venidá de México a España, de donde la Magestad del Rey don Philippe Tercero Nuestro Señor me mandó le viniesse a seruir en su Real Consejo de Indias, me hallé tan nescesitado, que si mis señores y amigos no me socorrieran, haziéndome vnos dellos préstamos de dineros y otros esperándome de su voluntad por algunos dineros que les debía,

${ }^{9}$ Censo perpetuo: "Es la constitución sobre cosa immueble coherente al suelo por la cual queda obligado el comprador a pagar al vendedor cierta pensión cada año, contrayendo también la obligación de no poder enajenar la casa o heredad que ha comprado con esta carga, sin dar cuenta primero al señor del censo perpetuo para que use de una de dos acciones que le competen" (Aut.).

${ }^{10}$ Incluido al final de este documento en la nómina de los "testigos ynstrumentales" de la pareja.

1 Legítima: "La parte de la herencia que según ley pertenece a cada uno de los hijos legítimos, en los bienes que quedaron por muerte de sus padres" (Aut.); "Porción de la herencia que el testador no puede disponer libremente, por asignarla la ley a determinados herederos" (DRAE).

12 Arras: "Donación que el esposo hace a la esposa en remuneración de la dote o por sus cualidades personales, y la cual no puede exceder, en Castilla, de la décima parte, y en Navarra, de la octava de los bienes de aquel" (DRAE). 
no fuera posible yo venir a España, ${ }^{13}$ que lo que a cada uno dellos debo lo dexo declarado en vn memorial firmado de mi nombre, y los bienes que por mi muerte quedan (que son los que en otra cláusula

13 Es un hecho que Eugenio de Salazar viajó, en su retorno al Viejo Mundo, dentro de uno de los barcos que componían la flota del general don Juan Gutiérrez de Garibay, surta en el puerto de San Juan de Ulúa entre el 8 de septiembre de 1599 y el 29 de febrero de 1600 (AGNM, General de parte, tomo 5, exps. 372,738 y 762 , fols. $83 \mathrm{v}, 155 \mathrm{v}-156 \mathrm{r}$ y $160 \mathrm{v}-161 \mathrm{r}$ ). Podría resultar un verdadero rompecabezas definir con certeza si nuestro autor regresó a España en la misma flota donde, a la sazón, había tomado pasaje el futuro dramaturgo Juan Ruiz de Alarcón. No obstante, lo más seguro es que ambos personajes hicieron juntos ese viaje. Según se desprende de los papeles manejados por diversos auiores, Ruiz de Alarcón "adelantó" unos meses su travesía al Viejo Mundo, ya que al parecer salió de México a fines de 1599 o principios de 1600 , en la flota comandada por aquel jefe naval. Los papeles conservados en nuestros archivos muestran que esta armada salió bastante tarde con destino al Viejo Mundo. En 1599, los ataques holandeses realizados sobre las costas españolas paralizan el retorno de las flotas americanas. Las 40 naves registradas en la flota que partió tardíamente de la Nueva España, a mediados de 1600 , comienzan a arribar a la península a partir del 9 de octubre de este año (CCS, cuenta 2899, libro 1, fol. 140v apud Chaunu 4: 106-111). Tras ocho meses de retraso, la armada en la que el comediógrafo supuestamente pasó al continente europeo - al mando de Gutiérrez de Garibay_. "logró zarpar" de La Habana dos días después de la fiesta de Reyes y "llegó" a Sevilla los primeros días de mayo (FernándezGuerra y Orbe 23-24; King 64-65). He localizado en archivos locales la tabla de salarios recibidos por nuestro autor durante el último lustro de su estancia en la Nueva España, entre el 2 de enero de 1595 y el 22 de marzo de 1600. Según se desprende de esos papeles, todavía en esta última fecha recibió la suma total de 642 pesos y 7 tomines de oro común, como pago por el ejercicio de su oficio de oidor en la Real Audiencia de México. "El doctor Eugenio de Salazar, oidor desta Real Audiencia - expresa la portada de este legajo-, con 800 mil maravedies de salario por año en la Real Hacienda." (AGNM, Real Hacienda, leg. 424-87, fols. 1r-2v). Ciertamente. resultan un tanto extrañas las quejas de Salazar, lamentándose de sus necesidades económicas, cuando en los libros hacendarios de México existe el cargo de un préstamo de 500 pesos de oro común que él mismo depositó a favor de la Corona el 30 de mayo de 1599, ante el tesorero Juan de Aranda y por mano de su corredor don Luis de Betanzos. El contrato plantea la condición de que si el dueño de aquel capital tenía que viajar a España antes de cierto plazo, tal suma se le habría de pagar "para cuando haya de irse" (AGNM, Real Hacienda, leg. 1292, fols. 230r-230v). El 15 de julio de 1600. el magistrado aún permanecía en territorio novohispano, ya que todavía se conserva un documento que comprucba su oportuna participación, como encargado del virrey don Gaspar de Zúñiga y Acevedo, conde de Monterrey, en los asuntos relativos al translado oficial de la Vieja a la Nucva ciudad de Veracruz (AGNM, General de parte, tomo 5, fol. 208rv). 
deste testamento declaro), no son bastantes para la paga de las dichas deudas. Por tanto, ruego mucho a mi buena muger que si Su Magestad le hiziere merced, como yo espero tenga por bien, que della se pague de mis deudas lo que se pudiere pagar, reseruado su honesto y moderado sustento. Y si mis obras se imprimieren, todo lo que dellas procediere se dé a mis acreedores hasta la concurrente quantidad de las deudas.

$10^{\circ}$. Declaramos que tenemos por sieruos nuestros a Gaspar Nalú ${ }^{14}$ y Catalina Biafra, ${ }^{15}$ su muger, y cinco hijitos suyos llamados Petronila, Catalina Ventura, Francisquito, Gasparito ${ }^{16}$ y Mariquita; y más tenemos a Diego Balanta ${ }^{17}$ y Joana Bran, ${ }^{18}$ su muger, todos morenos, a los quales todos tenemos amor, por habernos seruido bien y haber muchos años que los mayores nos siruen y haber los hijos delloss nascido y criádose en nuestra casa. Por tanto, yo la dicha doña Catalina Carrillo les doy libertad a todos y a cada uno dellos y los hago libres y no subjetos a seruidumbre alguna, con tanto que todos ellos siruan al dicho doctor Eugenio de Salazar, mi señor y marido, todos los días que él viuiere y le siruan muy bien, y después que Dios le lleue desta vida queden todos los dichos esclauos libres, y se den al dicho Gaspar Nalú cient ducados de mis bienes para que ponga algún tratillo ${ }^{19}$ con qué se sustente, y a la dicha Joana Bran se den cinquenta ducados para el mismo effecto. Con lo qual yo, la dicha doña Catalina, me aparto y desisto de todo lo que me pucde pertenecer por razón de mi dote y

14 Los negros Nalis aparecen registrados entre las tribus de los ríos de Guinea, cuyos miembros ocupaban las tierras situadas entre el río Geba y el río Núnez, ambos cercanc: al Cabo Verde (Aguirre Beltrán 118 y 333).

${ }^{15}$ La tribu Biafra fue una de las más tempranamente conocidas en México, aunque al parecer tuvo un escaso número de representanles. Los Biafaras, Biafadas o Biafare's, por el contrario, fueron grupos de esclavos negros que en el siglo xvi proporcionaron un considerable contingente en las cargazones dirigidas a la Nueva España. En nuestros días, por el año de 1967, la provincia de Biafra proclamó su independencia respecto de Nigeria, pero poco ticmpo después el ejército biafreño ofreció su rendición (Aguirre Beltrán 100,118,136,137,181, 241 y 333).

16 Francisquilo y Gasparito murieron poco tiempo después de la firma de este pliego testamentario, según el codicilo correspondiente (ver abajo).

17 Los negros balantes también pertenecían a la zona de Guinea (Aguirre Beltrán 117).

${ }^{18}$ La tribu Bran entró en nuestro territorio en múmero muy elévado durante el siglo XVI, andue con esta designación figuraban numcrosos esclavos Brong, Abrón o Besocs, confundidos entre sí (Aguire Beltrán 128).

19 Tratillo: "Trato que produce poca utilidad o ganancia, por el poco valor de los géneros" (Aur.). 
arras, en que soy la acreedora más antigua del dicho doctor Eugenio de Salazar, mi marido.

11․ Declaro yo, el dicho doctor Eugenio de Salazar, que desde el principio del año de mil y quinientos y cinquenta y ocho he seruido continuadamente a las Magestades de España ${ }^{20}$ en officios de justicia en España y en las Islas de Tenerife y La Palma ${ }^{21}$ y en la Audiencia

20 La célebre Carta de los Catarriberas, redactada al parecer el 15 de abril de 1560 , se halla dirigida a don Juan Hurtado de Mendoza, señor de la villa de Fresno de Torote. Ofrece una completa clasificación de los diversos tipos de empleados públicós que componían el "lucido" escuadrón burocrático de Felipe II. En uno de los parágrafos de esta epístola, Salazar declara que ya por el mes de noviembre del año anterior tuvo que aceptar el rango de "catarribera". No obstante, en otro documento, fechado en Congosto el 24 de agosto de 1559, él mismo afirmó que todavía a la sazón no había desempeñado cargo alguno (Cioranescu 15). El 18 de abril de 1564, el magistrado tomó residencia al justicia mayor de Mondéjar, según comisión de don Luis Hurtado de Mendoza, marqués de Mondéjar. Dentro de esa misma colección epistolar, la Carta I se halla fechada aproximadamente en 1567. Enviada a don Juan de Castejón, un hidalgo amigo del autor, tal misiva presenta a su vez una nueva crítica a las ambigüedades e irracionalismos de la corte madrileña. La Carta V se encuentra dirigida al licenciado Agustín Guedeja, relator del Real Consejo de Su Majestad. Aunque carece de fecha, esta epístola describe la villa de Tormaleo (Asturias), pueblo en donde nuestro escritor igualmente cubrió uno de sus primeros cargos como burócrata de la Co. rona (Salazar 2: 283-310). El soneto autobiográfico incluido en la Silva ofrece también algunos indicios sobre estas ocupaciones iniciales: "Las Salinas Reales fuy juzgando; / puertos de raya a Portugal vezina. / Juez Pesquisidor fuy a la contina, / y estube en las Canarias gobernando" (Silva, fol. 302r).

21 El título real que convirtió a Salazar en gobernador de las Islas de Tenerife y La Palma aparece firmado en Madrid con fecha del 31 de julio de 1567: "Embarcó rápidamente para Canarias, en unión de su familia, y tomó posesión de su nuevo cargo en la sesión del Cabildo tenerifeño celebrada en 25 de octubre de 1567. Un año más tarde, el 10 de noviembre de 1568 , bautizaba a su hija, Eugenia, en la iglesia de los Remedios de la ciudad de La Laguna" (Cioranescu 16). En su testamento, Salazar no hace alusión a esta hija, la cual sin duda murió siendo muy pequeña. Por llevar el mismo nombre del poeta, la niña también resulta homónima de la nieta natural a la que él mismo hace alusión en este papel (cláusula 18 ). La Isla de Tenerife es la mayor del archipiélago canario, con 2057 kilómetros cuadrados. Por el tiempo de la gubernatura de Salazar. Tenerife se encontraba densanente poblada por mercaderes castellanos, iralianos, portugueses y hasta flamencos. Según el testimonio de Gaspar Frutuoso en su libro Sandades da terra en las Islas Canarias (1590), la ciudad de Santa Cruz de La Palma —capital de la isla- era "tan vana y soberbia, tan lozana y bien provista, tan suelta en la injusticia y tan dada a deleites con su fertilidad, y tan libre y señora, que no temía la adversidad, ni recelaba el castigo" (Romeu Palazuelos 64). 
de Sancto Domingo de la Española, ${ }^{22}$ y en el patrocinio de su Real Fisco en las Audiencias de Guathemala ${ }^{23}$ y México y de oidor de aquella Real Audiencia, ${ }^{24}$ y v́ltimamente en officio de consejero del Rey Don Philippe Tercero Nuestro Señor en su Real Consejo de In-

${ }^{22}$ Eugenio de Salazar entregó la vara del gobiemo de las Islas Canarias a su sucesor, el doctor Gante del Campo, el 23 de abril de 1570. Durante cuatro años de espera para obtener un nuevo nombramiento, el poeta sufrí una difícil situación económica en el archipiélago, hasta que con fecha del 13 de diciembre de 1573 obtuvo el cargo de oidor en la Real Audiencia de Santo Domingo, según el título correspondiente que se conserva en Sevilla (AGI, Audiencia de Santo Domingo, leg. 899, fol. 283v-284v). Existe un poder del artista a favor de su padre, otorgado el 13 de enero de 1574 ante el escribano público Alonso Cabrera de Rojas para cobrar en su nombre la ayuda de costa de mil pesos de oro común que le había sido concedida por el rey Felipe II, con el objeto de financiar su viaje a la Isla Española (Cioranescu 18-19). Por otros documentos fechados el 18 de febrero siguiente, tengo noticias de que Salazar en esa travesía oceánica no sólo estuvo acompañado por su mujer e hijos, sino también por una sobrina, dos dueñas, dos mujeres de servicio, cuatro criados blancos y tres esclavos negros libres de derechos. Si cotejamos a estas personas con las citadas en la cláusula anterior, es evidente que la suma global de la gente de color se multiplicó en América con el paso de los años (AGI, Indiferente General, leg. 3089, fols. 158r-158v apud Morales Padrón 1: 212-213).

${ }^{23}$ Emitida en el Monasterio de El Escorial el 11 de julio de 1576, la real provisión que acredita a Eugenio de Salazar como Procurador Fiscal y Promotor de Justicia de la Audiencia de Guatemala impone, entre otras cosas, un salario anual de 750 mil maravedíes (AGI, Audiencia de Guatemala, leg. 394, fols. 228v-230r). Sin embargo, antes de viajar a Américá, el oficial firmó una escritura de poder el 25 de octubre siguiente a favor del licenciado Francisco de Vera, con el propósito de que éste cobrara en Madrid a su nombre los bienes heredados tras el fallecimiento de su padre, muerto por aquellos días. Posteriormente, en una carta personal escrita en Guatemala el 13 de marzo de 1577, el magistrado registra su llegada a esta provincia al principio de aquel año. Dentro de un legajo conservado en el Archivo de Indias, figuran asimisino nueve cartas redactadas por Salazar en tierras guatemaltecas a partir de esa lecha, la última escrita el 20 de mayo de 1582 (Cioranescu 19-20 y 211).

${ }^{24}$ Ya desde el 5 de junio de 1581 el licenciado Eugenio de Salazar aparece en las nóminas burocráticas americanas con el cargo de Fiscal de la Real Audiencia de México, pero todo parece indicar que el viaje a la Nueva España para cubrir esta nueva plaza no se realizó sino hasta mediados del año siguiente (AGI, Audiencia de Guatemala, leg. 395, fol. 64rv). A pesar de que el título original de este empleo aún se conserva, no existen en nuestros archivos mayores noticias sobre la fecha exacta del arribo de nuestro autor a la capital novohispana. Muerto el virrey don Lorenzo Suárez de Mendoza, conde de la Coruña. el 19 de junio de 1582, entró a gobernar en México la Real Audiencia, sólo compuesta al parecer por los licenciados Pedro Farfán, 
dias, ${ }^{25}$ y afirmo que por seruir a sus Magestades con amor y limpieza (como por la bondad de Dios les he seruido), y por los muchos gastos de tan largos caminos de tierra y viajes de mar, he gastado y consumido los salarios de mis officios y todo mi patrimonio y la dote de $\mathrm{mi}$ muger siruiendo, y no dexo otros bienes más que mis libros y vna tapicería y vn cauallo y vn poco de plata labrada de mi seruicio y poco mueble de mi casa y los vestidos míos y de mi muger, que no son de precio; por lo qual, atreuiéndome a la magnanimidad de mi Rey y Señor y conforme esperança que lleuo en su real benignidad y largueza para el remedio de mi pobre muger, que es bien nascida y muy enferma y de mucha edad, supplico humilíssimamente a su Ma-

Juan Sánchez de Paredes, Francisco de Sande y Hernando de Robles. Por el tiempo en que Salazar llegó a nuestro territorio, de cualquier modo, don Pedro Moya de Contreras -respaldado con la triple investidura de inquisidor mayor, arzobispo y virrey-, suspendi6 y privó de la "loga" o "garnacha" a varios oidores de la localidad. El 23 de abril de 1583 los oficiales reales instalados en la ciudad de Guatemala fueron reconvenidos por "entremeterse" con una permuta en cierta deuda contraída por el poeta en esa provincia, transfiriendo el pago respectivo a la ciudad de México, lugar a donde había sido promovido (AGI, Audiencia de México, leg. 13, fols: 8r10r; AGCA, Guatemala A1. 23, leg. 1513, exp. 174, fol. 627r; Cavo 66). A este mismo año remite el "Argumento" en verso que escribió quiză ya en tierras mexicanas para presentar el texto del tratado intitulado Diálogos Militares (México 1583), escrito por el doctor Diego García de Palacios y publicado por el impresor novohispano Pedro Ocharte. Posteriormente, el 20 de abril de 1584, las autoridades novohispanas juzgaron conveniente solicitar al rey la creación de un segundo puesto de fiscal en la Real Audiencia local "para que uno assista a la sala de lo cibil y otro en la del crimen, por los muchos negocios que ay" (AGI, Audiencia de México, leg. 1064, fols. 105r105v). A fines de ese año, Salazar aún figura con el cargo de fiscal real en el testimonio de las posturas que se hicieron para la venta de los oficios de ensayador y fundidor en la Casa de Moneda de México (Paso y Troncoso 12, $\mathrm{n}^{\circ}$ 722). El 14 de octubre de 1585, nuestro escritor todavía asistió con aquel título a las sesiones del III Concilio Provincial Mexicano, encargado de notificar a los eclesiásticos asistentes las cédulas reales que prohibían publicarlo, sin presentar antes los borradores a la Corona (Cuevas 2: 101). La cédula de su nombramiento oficial como oidor de la Real Audiencia de México, concedida localmente por estar enfermo el doctor Juan Sánchez de Paredes y suspendidos los doctores Pedro Farfán, Hernando de Robles y Diego García de Palacios - los oidores a ella adscritos--, corresponde al 2 de mayo de 1586. El título real ustenta, en efecto, una fecha tardía, diferida hasta el 9 de agosto de 1589 (AGNM, Duplicados de Reales Cédulas, tomo 2, exps. 188 y 371 , fols. $106 v$ y $205 v-206 r$ ).

25 El nombramiento de Eugenio de Salazar como miembro del Real Consejo de Indias - donde figura con el puesto número 67-, se halla furmado en la capital española el 27 de septiembre de 1600 (Schäfer 1356). 
gestad se duela della y de mí y se sirva de hazerle merced para su honesto sustento y para la paga de mis deudas, atento que no dexo hijo ni otra persona alguna en quien recibir merced, y ésta supplico humilíssimamente a su Magestad me haga en premio de mi largo y fiel seruicio y del que a las Magestades del Emperador y Rey don Phillippe Segundo, su auuelo y padre, señores nuestros que de Dios gozan, hizo Pedro de Salazar, mi padre, siruiendo a la Magestad imperial en la guerra de Alemaña a su propia costa y missión, y historiando y estampando las victorias y hazanas deste ínclyto auuelo y padre hasta el día de su muerte, y siruiéndole con la escritura dellas. ${ }^{26}$ Y ruego a mis aluaceas manden sacar esta cláusula de mi testamento y presentarla en el Real Consejo de Cámara de Indias, ante los señores dél, a quien suplico se siruan de consultar a Su Magestad ${ }^{27}$ con cháridad la pobreza en que queda mi buena muger y la nescesidad que mi ánima lleua de la paga de mis deudas para que me haga la merced que por tan buen medio se puede aspirar.

$12^{\circ}$. Iten, yo, el dicho Eugenio de Salazar, digo que vnos mil ducados poco más o menos que me quedaban de lo poco que de Indias traxe, Andrés de Herbás, ${ }^{28}$ mi amigo, vezino de Seuilla, me los remitió en

${ }^{26}$ El doble carácter de Pedro de Salazar como militar y cronista - puesto en duda por varios autores, entre los que destaca Cioranescu-, queda confurmado en este párrafo del testamento. Los títulos de los libros históricos por él escritos y publicados son los siguientes: Historia y primera parte de la guerra que don Carlos Quinto, Emperador de los romanos, rey de España y Alemania, movió contra los príncipes y ciudades rebeldes del reyno de Alemania y sucessos que tuvo (Nápoles: Juan Pablo Suganappo, 1548); Crónica de nuestro invictísimo Emperador Carlos Quinto deste nombre, empera. dor de los romanos, rey de España y de Alemania. En la qual se tracta la justíssima guerra que su magestad movió contra los luteranos y rebeldes del Imperio y los sucessos que tuvo. A la qual va agora nuevamente añadido el fin que las dichas guerras tuvieron. Año MDLII (Sevilla: Dominico de Robertis, 1552); Ystoria de la guerra hecha contra la ciudad de Africa con la destruyción de la villa de Monazter y la ysla del Gozo y pérdida de Tripol de Berbería con otras muy nuevas cosas (Nápoles: Casa de Mastre Matia, 1552) e Hispania Vitrix. Historia en la cual se cuentan muchas guerras sucedidas entre cristianos y infieles así en mar como en tierra desde el año de 1546 hasta el de 65, con las guerras acontecidas en la Berbería entre el Xarife y los reyes de Marruecos, Fez y Velez (Medina del Campo, Vicente de Mills, 1570). (EUIEA; Palau y Dulcet 18: 351-352).

27 "Va entre ringlones 'a su Magestad', vala", primera nota del autor al calce del documento (fol. 470v).

${ }^{28}$ Posiblemente pariente de la pareja compuesta por Juan Erber de Cervantes y doña Isabel del Corral, vecinos de la ciudad de Sevilla y padres del licenciado Erber del Corral, fiscal de la Real Audiencia de México en la 
letra de Jácome Mortedo, ${ }^{29}$ cambió con otros cinco mil y trezientos y setenta y tres reales que en la misma letra, que era de mil y quinientos ducados, vencieron inclusos y eran del señor don Joan de Fonseca, ${ }^{30}$ oidor de la Real Audiencia de México, que por orden suya los había

última década del siglo xvi. El 25 de febrero de 1593 este oficial novohispano presentó una información de sus méritos y servicios, aduciendo que era "hombre honrado y cuerdo, aunque para oficio de fiscal son menester más fuerzas y salud de la que él tiene" (Catálogo de pobladores $1941 \mathrm{n}^{\circ} 577$ ). En México, también existen rastros de un cierto Gonçalo de Eruás, el cual se avecindó en la capital novohispana desde época temprana. Inscrito én el padrón de los pobladores que se convirtieron en encomenderos, Eruás tuvo dos hijos durante su matrimonio, "la vna hija y el otro hijo". Sin embargo, los papeles donde aparece esta información no ofrecen los nombres de sus descendientes, sino únicamente que toda la familia vivía en la necesidad al reportarse como "pobre". (Icaza 2, n 815).

${ }^{29} \mathrm{Al}$ estudiar la dinámica actividad comercial de Sevilla, Domínguez Ortiz menciona los casos de los banqueros foráneos asentados en la capital andaluza: "El núcleo mercantil sevillano fue, sin duda, el más abigarrado del mundo. Allí se dieron cita mercaderes vascos y castellanos, extranjeros de muchas nacionalidades $y$, en menor número, también andaluces contagiados por aquella fiebre de negocios [...]. Entre los extranjeros se encuentran un número corto pero muy relevante de flamencos (Jácome, Colarte, Vint, Lila...), bastantes franceses, muchos portugueses, sobre todo después de la unión de ambas coronas, algunos ingleses, alemanes y muchos italianos, algunos de ellos de renombre" (Domínguez Ortiz 1973 3: 146-147).

${ }^{30}$ El 5 de mayo de 1595, el licenciado Juan de Fonseca, oidor de la Real Audiencia de la Nueva España, obtuvo su incorporación al grado de doctor en cánones en la Real y Pontificia Universidad de México. Las insignias doctorales le fueron impuestas en un claustro pleno, presidido por sus dos padrinos de profesión, los también oidores Antonio Maldonado y Francisco Tello. A fines de ese mismo año, ocupó el puesto de rector de aquella institución educativa con todos los votos a su favor, casi siguiendo en el cargo al propio Eugenio de Salazar, quien también por su parte lo había desempeñado tres años antes. Durante el periodo de su rectorado en la capital novohispana, Fonseca tuvo ocasión de administrar el dinero de la Universidad que había permanecido en poder del depositario general $y$, asimismo, conseguir una finca idónea para imponer aquel capital (Plaza y Jaén 1: 168-174). Antes de viajar a la Nueva España, Juan de Fonseca también había trabajado como oidor en la provincia de Guatemala, donde al parecer se casó con doña Catalina Scdeño, hija del también magistrado don Mateo de Arévalo Sedeño, fiscal de aquella localidad y luego oidor en México. Cuando menos en dos ocasiones -el 27 de julio de 1601 y el 27 de febrero de 1602_. Fonseca recibió la comisión oficial de visitar el desagüadero de Huehuetoca en los ejidos anexos a la ciudad de México, junto con Francisco Millán y Francisco Núñez Cano. Murió ejerciendo su empleo en tierras mexicanas, ya que el 28 de abril de 1605 su viuda presentó una petición de ayuda de costa para remediar la pobreza en que la había dejado. Según las palabras de esa mujer. 
yo de dar y pagar en esta corte a personas a quien su merced los debía, y viniendo como vino la dicha letra sobre vn Andrés de Haro, ${ }^{31}$ correspondiente del dicho cambio, y habiéndola él aceptado, sucedió que antes que se cumpliese el plazo della, él y el dicho Jácome Mortedo quebraron, y la dicha letra no se ha cumplido, y está en duda si se pagará; mando que lo que della se cobrare, se reparta entre el dicho señor don Juan de Fonseca y mi heredero por rata de lo que cada vno heredaba en la dicha letra, y de lo a mí perteneciente se den al dicho Andrés de Herbas trezientos ducados que me prestó a quenta de lo que de la dicha letra se cobrare.

13․ Más digo que yo dexo entre mis libros quatro escritoritos de mi mano, enquadernados en pergamino, los dos de marca de pliego, otro de quarto de pliego y otro de ochavo, que los mayores están intitulados con vn título que dize Casus responssa siue allegationes et a hic lucubrationes Eugenii Sanazari. Y el título del mediano dize Repertorium laborum meorum. Y el del menor, que tanbién es a manera de repertorio, dize Grana aurea viriusque iuris, atque sacrae pagine, que todos quatro libros son de estudios míos jurídicos. ${ }^{32} \mathrm{Y}$ assímismo dexo otros dos libros escritos, el vno de mi mano y de la de Fernando, mi hijo que está en el cielo, cnquadernado en tablas y cuero colorado en que están mis obras en verso, y cartas mías en prossa, y el otro, de mano agena y mía, enquadernado en cuero leonado y dorada la enquadernación, donde están las mismas Obras de poessía sacadas en limpio

Fonseca había muerto muy pobre y con una enorme cantidad de deudas, dejándole además una hija natural de cuyo remedio ella tuvo que hacerse cargo (Catálogo de pobladores $1941 \mathrm{n}^{\circ}$ 828; Dorantes de Carranza 273; Porras Muñoz 245; Guía 1987 nos 72 y 138).

${ }^{31}$ No sería extraño que este Andrés de Haro fuese ascendiente directo del famoso negociante Simón de Haro, prior del Consulado de México en 1650. cuya fortuna se llegó a estimar en 600.000 pesos y cuyo prestigio estaba fincado sobre todo en la riqueza amasada dentro del comercio atlántico y pacífico (Lynch 2: 283).

32 Graduado en cánones por la Universidad de Sigüenza, según él mismo declara en el soneto donde propone su "autobiografía", el madrileño Eugenio de Salazar presentó en la Universidad de México los títulos de bachiller y licenciado - "buenos" y "bastantes"- al obtener en esa institución el grado de doctor, con fecha del 23 de agosto de 1591 (AGNM, Universidad, tomo 6, fols. 174v-177r). En su examen doctoral el sustentante propuso cn latín una "cuestión canónica", a la que arguyeron en esa misma lengua los doctores Andrés Zaldiema de Mariaca, Juan Fernández Salvador y Juan de Salcedo. En su Bibliotheca Hispana-Nova, Nicolás Antonio considera a nuestro autor como un "juris doctor, rerum Indicarum senator regius", experto a la vez en las lenguas latina y española (Antonio 1: 362). 
y algunas de las dichas cartas en prossa. ${ }^{33} \mathrm{Y}$ tanbién dexo otra obra mía en verso intitulada Nauegación del alma, con vna enquadernación leonada y dorada, dedicada a la Magestad del Rey Nuestro Señor, escrita de mano. ${ }^{34} \mathrm{Y}$ dexo otro libro enquadernado en cuero lconado y dorado en que están las obras que hizo e imprimió el dicho mi padre. Ruego a mis albaceas que los tres libros de poesía referidos se guarden hasta ver si ay orden de imprimirlos, conforme a lo que digo en la cláusula siguiente, y de los demás que he dicho de mis estudios en esta cláusula vean cómo se podrán mejor aprobechar y de otro libro grande de marca de pliego, escrito de mano de diuersas letras, que todo él es de Auisos tocantes al buen gobierno y seguridad de las Indias. ${ }^{35}$

$14^{\circ}$. Iten, digo què yo he procurado juntar y sacar en limpio otros estudios míos demás de los referidos en la cláusula precediente, los quales tengo enquådernados en vn libro cubierto con pergamino azul dorado, con vn tílulo que dize De peculiaribus curiarum Noui Orbis. $\mathrm{Y}$ los mismos, en otro libro grande enquadernado en cuero leonado con cintas amarillas, y otro de menos hojas enquadernado tanbién en cuero leonado y dorado y cintas amarillas. Y esta misma obra dexo v́ltimamente sacada en limpio, mas emendada y añadida, escrita de mano en tres cuerpos de pliego enquadernados en pergamino, con rayas azules y cintas verdes. Deseo que si yo dexare despachado priuillegio para la impressión desta obra. se imprima a costa de mis bienes, si los huuiere, y si no, se procure tomar asiento con algún impressor, de manera que él la imprima a su costa y quede para mis acreedores partes de la ganancia. Y si esta obra se imprimiere, se procure tanbién priuillegio para la impressión de mis Obras de poessía ${ }^{36}$ y se impriman tomando tanbién asiento v́til con algún impressor, y la impressión

${ }^{33}$ Es difícil precisar a cual de estos dos volúmenes corresponde el ms. Silva de poesía, conservado actualmente en la biblioteca de la Real Academia de la Historia de Madrid (ms. C-56, 505 fols.), y en cuyas páginas aparecen transcritas tanto sus obras en verso como sus cartas.

${ }^{34}$ El códice original que contiene la Nauegación del alma por el discurso de todas las edades del hombre, se custodia con estas mismas características y en perfecto eslado de conservación en la Biblioteca Nacional de Madrid (ins. 3,669, 79 fols.).

${ }^{35}$ En el Epítome de la Biblioteca Oriental i Occidental, Náutica i Geográfica, de Antonio de Lcón Pinelo, y en la Bibliotheca Hispana-Nova, de Nicolás Antonio, se proporciona este mismo título con algunas variantes: "De los negocios incidentes en las Audiencias de las Indias... Lat. i Romance, m.s.f." (León Pinelo 116; Antonio 1: 362).

36 Véase nota 33. 
destas Obras de poessía se ha de hazer por el libro leonado y dorado, donde ellas están más añadidas y corregidas, y por el de la Nauegación del alma, de que he hecho mención en la cláusula precediente. Y la dedicación de las obras de derecho se haga a su señoría del señor licenciado Laguna, ${ }^{37}$ presidente del Real Consejo de Indias, que debo este seruicio y otros muy mayores a su señoría, por las muchas mercedes que me ha hecho, y esta dedicación se saque del libro grande enquadernado en cuero leonado dorado de que arriba he hecho mención, donde al principio dél está escrita. Y si las Obras de poessía se imprimieren, se dediquen todas a la Magestad del Rey Nuestro Señor, a quien tengo dirigida la Nauegación del alma, y supplico a Su Magestad perdone mi atreuimiento. ${ }^{38}$

$15^{\circ}$. Iten, digo que entre mis papeles quedan recaudos de deụdas antiguas mías que he pagado. Y quedan libros de mano que dexó el dicho Fernando de Salazar, ${ }^{39}$ mi hijo que Dios aya. Y quedan algunas obras

${ }^{37}$ El licenciado Paulo de Laguna fungió como árbitro ante las Cortes españolas, tanto a funes del siglo XVI como a principios del XVI, sobre todo mientras duró la preocupación mostrađa por algunas autoridades por conservar los bienes del reino. Junto con otros magistrados del Real y Supremo Consejo de Indias, en el cual fue inicialmente consejero, Laguna refiere cómo en 1592 la Corona había inandado regresar a Madrid a numerosos jueces desperdigados por el país que tenían el encargo de vender las tierras baldías. Con esa orden, el Monarca acallaba las protestas emitidas por algunos organismos provinciales ante la venta indiscriminada de los terrenos que pertenecían a la comunidad en algunos pueblos españoles (Salomon 143). La papelería general de documentos de América conservados en la Biblioteca Nacional de Madrid, incluye una carta del licenciado Paulo de Laguna, escrita ya cuando despachaba como pretidente del Consejo de Indias y fechada el 14 de enero de 1603 en la ciudad de Valladolid. Dirigida a don Juan Manuel de Mendoza y Luna, marqués de Montesclaros, es una misiva de felicitación por el nombramiento de este personaje al cargo de virrey" de la Nueva España (Paz no 297-4).

38 "No se han de imprimir las cartas en prossa [Rúbrica]", segunda nota autógrafa del testador, que aparece escrita al margen en el manuscrito original (fol. 471v).

39 A la cabeza de un soneto laudatorio escrito en Guatemala durante el periodo en que su padre ocupó el puesto de fiscal en ese lugar, Fernando de Salazar Carrillo se presenta como "natural de Madrid" y "discípulo del excelente poeta Francisco de Pedroza". Tal composición, cuyo primer verso dice "Espadas griegas, tan etemizadas", figura en las páginas preliminares de la obra intitulada La Austriacha, redactada en latín por ese escritor avecindado en tierras guatemaltecas y conservada aún inédita en Madrid. La estancia delineada en honor de este mismo autor por Pedro de Salazar Carrillo -quizá el menor de los hermanos-, está dedicada "a la real villa de Madrid", ya que él también se declara "hijo della" y "discípulo dél" (Francisco de Pedroza, La Austriacha, Biblioteca Nacional de Madrid, ms. 3960, fol. 3rv). 
de las que escribió y no imprimió el dicho mi padre, y entre ellas las nouelas o quentos con que siruió a la Magestad del Rey Don Philippe Segundo Nuestro Señor que está en el cielo, escritas de mano en quadernos. ${ }^{40}$ Ruego a mis albaceas procuren que estos papeles se aprobechen, y en especial estas Nouellas porque cierto tienen ingenio y gustoso y honesto entretenimiento.

$16^{\circ}$. Iten, ambos Eugenio de Salazar y doña Catalina Carrillo dezimos que por lo bien que nos han seruido María de Figueroa, ${ }^{41}$ nuestra criada, y Gerónimo de Reyna, ${ }^{42}$ su marido, hemos deseado se huuiera ofrecido algún officio o entretenimiento en Indias en qué acomodarlos, y no ha habido ocasión para este effecto, de que nos pesa mucho, y porque creemos se querrán voluer a la Nueua España. de donde son naturales, mandamos se les den trezientos pesos de a ocho reales de

40 En efecto, aún existe un volumen con las diez novelas todavía inéditas que produjo el capitán Pedro de Salazar, preparadas recientemente para su edición en Clásicos Castellanos. Subastado en la sala Sotheby's de Londres e] 16 de junio de 1970 , el manuscrito original que contiene estas narraciones fue adquirido por don Bartolomé March, después de haber permanecido oculto durante largo tiempo dentro de la colección de piezas de la historia literaria española que compiló en su biblioteca sir Thomas Phillips (17921872), donde figuraba con el número 2,238 (Blecua Pardiñas 92-93). En la Dedicaloria incluida en el códice de la Navegación del alma. Salazar hace alusión igualinente a este corpus finnado por su progenitor: "También escrivió un agradable libro de novelas o quentos, con que sirvió a Su Magestad en el tieinpo de su felizisima iuventud; obra adaptada para alguna recreación y gustoso entretenimiento de aquella su edad dorada" (Navegación, fol. 11v).

41 Citada en el codicilo que transcribo a continuación, María de Figueroa estaba casada, como vimos, con Gerónimo de Reyna, y era madre seguramente del paje Diego de Reyna mencionado igualınente en ese Jugar. Por las recomendaciones que recibe en nuestro Documento 2, es posible pensar que al escribir Salazar aquella nueva memoria testamentaria esta mujer ya había quedado viuda.

42 Gerónimo de Reyna, alguacil en la gobernación de la Nueva España, recibió el 19 de agosto de 1599 una comisión del virrey don Gaspar de Zúñiga y Acevedo para que, con guarda de justicia, llevase custodiado a Lucas de Lara hasta la ciudad de Guadalajara, capital de la Nueva Galicia (AGNM, Gincral de parte, tomo 5, exp. 326, fol. 72rv). Es uno de los testigos que figuran al calce del testamento, legalizado el $1^{\circ}$ de mayo de 1601 por el escribano público Pedro Duarte. Con tal certificación, el testamento autógrafo quedó registrado en los protocolos de este notario, ya que realinente los pliegos que lo contienen carecen de fecha. La firma de Reyna aparece un poco borrosa, pero es claro que él sí sabía escribir, a diferencia del calcetero Antonio Morán, quien tiene quc excusarse por no saber hacerlo (Documento 1, fol. 474r). 
nuestros bienes, y demás desto y de lo que siempre hemos hecho por ellos, quisiéramos hallarnos sin otras deudas más precisas para que mejor vieran la buena voluntad que les tenemos, la qual reciban.

$17^{\circ}$. Iten, dezimos que hemos criado y enseñado en nuestra casa a María, nuestra criada huérfana, que yo la dicha doña Catalina he querido tome mi appellido y se llame María Carrillo, ${ }^{43}$ y porque por haberse criado en nuestra casa y seruicio la tenemos amor y buena voluntad y no la hemos podido casar y deseamos que no venga a menos, mandamos que de nuestros bienes se le den ciento y cinquenta ducados con que se vista y se ponga en seruicio de alguna señora que la trate muy bien, de lo qual rogamos a nuestros albaceas por caridad se encarguen, que harán a Dios seruicio en ello.

$18^{\circ}$. Y ambos los dichos doctor Eugenio de Salazar y doña Catalina Carrillo, marido y muger legílimos, dezimos que, pues nuestro Señor ha sido seruido lleuar para sí nuestros hijos ${ }^{44}$ y nos hallamos sin succesión legítima y forçosa, y el amor que en vida nos hemos tenido y tenemos es justo le tengamos y mostremos en nuestra muerte: nos instituimos el vno al otro por heredero vniuersal de todos nuestros bienes, de manera que el que Dios fuere seruido que sobreuiua succeda y herede al otro, en el remanente de sus bienes, cumplido y pagado lo que en este testamento queda dispuesto. Y porque nuestro hijo Fernando de Salazar Carrillo que Dios aya en su testamento declara que dexa vna hija natural ${ }^{45}$ de edad de tres años, en poder de su madre ${ }^{46}$ en la ciudad de Salamanca, la qual hasta agora no hemos visto: quere-

${ }^{43}$ Hija adoptiva de la pareja, María Carrillo figura asimismo en el codicilo respectivo con una especial recomendación del testador.

${ }^{44}$ Los dos hijos varones. Fernando y Pedro de Salazar Carrillo, lograron alcanzar la edad adulta, según lo demuestra el prólogo de la Silva de pocsía, ordenada al parecer en México por la ubicación delineada en la frase "si alguno de vosotros fuere Dios seruido que venga a México". En tales páginas preliminares también destaca la orden que el autor hace llegar a ambos hermanos, conminándolos a escribir algunas piezas encomiásticas para su libro: "Haga Fernando vna dozena de sáphicos y adónicos, vna oda en recomendación de la obra de su padre, y vn buen soneto; y Pedro otra obrita a manera de canción, remedando a alguna de las que van en la Silua, y otro soncto, poniendo vuestros nombres" (Silva, fols. 2r-3v). La hija menor, según ya hemos visto, murió sin duda en la infancia (véase nota 21).

${ }^{45}$ A la muerte del poeta, su nieta obtuvo un respaldo monetario vitalicio de 200 ducados (Colección 1967. XIV: 183).

46 Doña Isabel de Monroy -madre de la hija natural de Femando de Salazar Carrillo-, recibió a su vez el 19 de abril de 1614 un señalamiento de 50 ducados como ayuda real, tras el temprano fallecimiento de la menor (Colcción 1967, XIV: 183). 
mos que si después de la muerte de ambos quedaren algunos bienes nuestros, pagadas nuestras deudas y cumplido lo que en este testamento disponemos, sean para la dicha hija natural del dicho nuestro hijo, a la qual en el entretanto el que de nosotros quedare viuo hará el bien que pueda.

$19^{\circ}$. Nombramos por nuestros albaceas testamentarios a nuestro padre y íntimo amigo Gaspar Moro, ${ }^{47}$ de la Companía del Nombre de Iesuús, y a Matheo Rodríguez de Alcántara, ${ }^{48}$ nuestro deudo, y al que de nosotros quedare viuo, a los quales y a cada uno dellos in solidum

47 Nacido en la ciudad de Valladolid (España), por los años de 1554 o 1557, el padre Gaspar Moro era hijo del licenciado Juan Moro y de doña María de Olmedo. En 1572, ingresó a la Compañía de Jesús en el colegio de Salamanca. A los veinticinco años de edad, deseoso de trasponer el océano Allántico, viajó a la Nueva España, formando parte de la expedición que llegó a tierras mexicanas el 7 de agosto de 1579. Todo parece indicar que, por el año de 1581, Moro se ordenó sacerdote. Un año después, por la época en que arribó Salazar a nuestro territorio, el jesuita ya impartía la cátedra de Dialéctica en el Colegio Máximo de San Pedro y San Pablo, en la ciudad de México. En 1583, Moro comunica a los superiores de la orden su intención de regresar a Europa, pero en una carta fechada al año siguiente, el padre general Claudio Aquaviva lo persuade de que "ningún título honesto podría tener su vuelta, habiendo partido de la provincia donde estaba con tan fervorosos deseos y esperanzas de hacer mucho fruto". El 20 de octubre de 1584 , la respuesta a esa llamada de atención alude a las "indisposiciones" y los "achaques" de Moro, imposibilitado para conducir la lectura de un curso de artes que impartía en el colegio de Puebla de los Ángeles. Por este motivo, aunque en un principio se le niega la autorización para retornar al suelo patrio, más adelante logra su propósito, no sin antes tener que sufrir algunos reveses. El padre provincial Antonio de Mendoza, en carta fechada el 15 de febrero de 1586, hace hincapié en cómo le habían quitado a Moro "algunas propiedades y singularidades y libertades que tenía [...], advirtiéndole del camino por donde ha de caminar". Por orden de este mismo clérigo, en 1589 pasó al fin a la provincia de Castilla. Instalado en la casa profesa y en el colegio de San Ambrosio de Valladolid con los cargos de confesor y predicador, el rebelde sacerdote deja transcurrir varios años. En 1601 -el año en el que fue nombrado albacea testamentario de nuestro autor-, fue señalado con fiereza por llevar una vida que "no era la más ejemplar", metido siempre en "negocios cortesanos" como administrador del marqués de Aguilafuente. Precisamente por "engolfarse" en "negocios seculares", Moro es tachado a la postre como un sujeto intrigante que ventilaba inás asuntos que los procuradores de corte. Hacia 1605, todavía administraba los bienes de ese personaje de la nobleza y, un año después, "desaparece" de la escena. Murió en Madrid el 2 de septiembre de 1609 (Zambrano 10: 432-443).

48 Vecino de Madrid, según la cláusula séptima de nuestro Documento 1. es también uno de los testigos que figuran al calce de este papel. 
damos poder qual se requiere para la execución y cumplimiento deste nuestro testamento y lo en él contenido, y para que para este effecto puedan entrar por su propia authoridad en nuestros bienes y mandarlos vender y disponer dellos en la menera que les parezca. Y reuocamos y anulamos otros qualesquier testamentos y codicillos que antes deste ayamos hecho y otorgado en qualesquier partes y lugares y queremos que este solo y no otro alguno valga como nuestro testamento verdadero y vltima voluntad nuestra que es, o por la vía que aya y pueda haber lugar de derecho y en firmeza dello lo firmamos de nuestros nombres aquí y en la cubierta deste testamento.

El doctor Eugenio de Salazar. Dona Catalina Carrillo [Firmas].

En la villa de Madrid, a primero día del mes de mayo de mill y seiscientos y vn años, ante mí el presente escriuano y testigos, paresieron presentes el señor doctor Evgenio de Salaçar del Qonsejo Supremo Real de las Yndias, y la señora doña Catalina Carritlo, su muger, rresidentes en esta dicha uilla de Madrid, y me entregaron a mí el presente scriuano sta scritura de testamento yn scristis cerrada y sellada, escrito en seis fojas, en todo y en parte de la letra del dicho señor doctor y rrubricadas de su rrúbrica y firmado al fin del de los nombres de los dichos señores doctor Salaçar y doña Catalina Carrillo, en el qual dejan hordenado cosass tocantes a sus ánimas y conçiencias, y en los hordenados albaceas y herederos quieren y es su boluntad que lo qontenido en él se guarde, cumpla y execute y que no se abra ni publique asta tanto que qualquiera de los dichos sea fallecido y pasado de la presente vida, y rrebocaron y anularon otros qualesquier testamento o testamentos que antes deste ayan ffecho, ansí por escrito como por palabra, que quieren que no balgan ni agan ffee y juramento ni fuera dél, salbo éste que al presente hacen y otorgan que quieren que valga por su testamento, v́ltima y postrimera boluntad, o por aquella uía e forma que mejor aya en general de derecho, y ansí lo dieron y otorgaron ante mí, el dicho scriuano, y testigos yuso escritos, testigos que fueron presentes a lo que dicho es, el licenciado Belorado Brutón ${ }^{49}$ y Matheo Rodríguez de Alcántara y Pedro Fernández Nuño y

${ }^{49}$ El licenciado Francisco Velorado Buitrón era abogado en la corte madrileña. Recibió bajo custodia "en su casa y poder" a doña Eugenia de Salazar - la niela natural del poeta-, según consta en los papeles adjuntos al testamento, incluido como ya hemos dicho en la curaduría incoada a nombre de esa menor. El 17 de octubre de 1602, al día siguiente de la muerte de nuestro autor, Velorado Buitrón acudió ante las autoridades de la ciudad de Valladolid para dar cauce a estos negocios. Con tales medidas, el alcalde Martín Fernández Puertocarrero nombró a Bartolomé Martínez, procurador 
Gerónimo de Reyna y Andrés López y Antonio Morán, calcetero, y Domingo López de Alayza, vezinos y estantes en esta dicha uilla y los dichos son presentes, y yo el presente scriuano doy fee que conozco a los presentes de sus nombres juntamente con los dichos testigos. Por Antonio Morán, que dijo no sauer firmar, firmolo por él vno de los dichos testigos.

El doctor Eugenio de Salazar. Doña Catalina Carrillo. Matheo Rodríguez de Alcántara. Domingo López de Alaica. Pedro Femández Nuño. Francisco Velorado Butrón. Gerónimo de Reyna. Testigo, Andrés López. Por testimonio Antonio Morán, Andrés López. Pedro Duarte, scriuano público, vno de los del número desta dicha villa de Madrid [Firmas].

\section{Documento 2}

Codicilo

En el nombre de Dios, amén. Yo el doctor Eugenio de Salazar, del Consejo Real de Indias, digo que después que otorgué mi testamento cerrado juntamente con doña Catalina Carrillo, mi amada muger, en la villa de Madrid, a primero del mes de mayo del año de 1601 por ante Pedro Duarte, escribano público y del número de la dicha villa, he acordado mudar la forma de mi entierro y ordenar algunas otras cosas. ${ }^{50}$ Por tanto, digo que ordeno lo siguiente:

Primeramente, que si Dios fuere seruido que yo muera en esta ciudad de Valladolid, se escuse en mi entierro todo género de pompa funeral y gasto no nescesario, pues todo eso no presta para el sufragio de las almas, y assí pido encareçidamente a mis albaceas que el día que yo muriere, vestido mi cuerpo con el hábito del señor San Francisco, se meta en vn ataúd que se cubra con una bayeta negra y en anocheciendo (si muriere de día), o al amanecer ${ }^{51}$ (si muriere de noche), se ponga en vn coche que para ello se alquile, y sea en él llevado al monasterio de los benditos ${ }^{52}$ religiosos carmelitas descalços, extramuros desta ciudad, donde está enterrado el cuerpo del señor licen-

de la corte, como abogado defensor de la interesada (APM, Protocolo 2695, Bartolomé Gallo (1600-1615), fols. 457r-476v).

50 "que conuienen al dis[...]", tachado en el original.

51 "o antes que amanezca", corregido en el original.

52 "benditos", agregado entre líneas en el documento. 
ciado Hernando de Saauedra, ${ }^{53}$ que Dios aya, buen amigo y compañero mío que fue del dicho Real Consejo de Indias, ${ }^{54}$ y junto a su sepultura a la mano izquierda me entierren, haziendo los benditos padres el officio conforme a la hora en que huuieren de enterrarme y para este officio se lleuen seis hachas que alumbren a la cruz de mi señor Jesucristo y las candelas nescesarias para los dichos religiosos, y en mi entierro no vayan más que vno de mis albaceas, el que más desocupado se hallare, y mis criados, y de ay a los días que a mis albaceas parezca, se me hagan las exequias con otra media dozena de hachas que alumbren la sancta cruz y las candelas nescesarias para el altar donde se huuiere de dezir la misa y para los religiosos, y se auise dos o tres días antes a su Señoría del Señor presidente y ${ }^{55}$ Consejeros de Indias, mis señores y amigos y compañeros, para que lo. sepan y hagan a mi memoria la charidad y merced que sean seruidos. Y las hachas del entierro y honras sean para el conuento de los dichos religiosos con más la limosna que a mis albaceas parezca por la sepultura y officios, la qual se les pague de mis bienes, y ruego mucho a la dicha mi amada muger que, si muriere en esta ciudad, se mande enterrar conmigo, para que, como hemos viuido juntos tantos anos, lo estemos muertos hasta que Dios nos mande llamar para el Vniuersal Juicio, de donde le suplico ${ }^{56}$ que por su piedad y clemencia $^{57}$ nos lleue juntos a

53 "qu Di", suprimido en el original.

54 El magistrado Fernando de Saavedra Valderrama — siendo oidor de la Real Audiencia de la Nueva España-, obtuvo las insignias doctorales en la Universidad de México el miércoles 19 de noviembre de 1586, de manos de su padrino el doctor Juan Fernández Salvador. En esa ocasión, el señor don Rodrigo de Vivero le calź́ las espuelas y le ciñ́6 la espada como nuevo doctor en cánones. Al año siguiente, estuvo propuesto como candidato al puesto de rector en aquella institución educativa, pero no es hasta el 10 de noviembre de 1588 cuando alcanza ese título, con todos los votos a su favor. El opositor al que se enfrentó fue el doctor Santiago del Riego, alcalde de corte. Un año después, vuelve a derrotar al mismo oponente, ya que fue reelegido en aquel cargo con especial "dispensación" del virrey don Álvaro Manrique de Zúñiga, marqués de Villamanrique. El 23 de agosto de 1590, en un claustro pleno de las mismas escuelas, Fernando de Saavedra Valderrama tuvo el honor de entregar la borla doctoral al licenciado Eugenio de Salazar, mientras que el Adelantado Miguel López de Legazpi le ceñía la espada y le calzaba las espuelas. Tras una fallida repostulación al cargo de rector de la Universidad de México en 1593, obtuvo nuevamente ese puesto el 10 de noviembre de 1594 (Plaza y Jaén 1: 134-168).

55 "y Señores", tachado en el original.

56 "le suplico", agregado entre líneas en el documento.

57 "mas le suplico", tachado en el original. 
su gloria, donde le demos gracias y alabanças eternas, amén.

Mando que a Diego de Reyna, mi paje, le den vn vestido de luto y más cinquenta ducados.

Declaro que después del v́ltimo testamento que hize, juntamente con la dicha mi muy amada muger, se nos han muerto dos negritos Francisquito y Gasparito de los que dexé declarados en el dicho testamento.

Y demás de los albaceas en el dicho testamento declarados, nombro por albacea mío al sef̂or licenciado Velorado de [Buitrón], ${ }^{58}$ abogado desta Real Corte, al qual supplico lo acepte y haga esta charidad a mi alma por seruicio de Nuestro Sefior y por hazerme a mí merced por la amistad $^{59}$ y amor que yo le he tenido.

Y quiero y es mi v́ltima voluntad que lo contenido en esta escritura valga y se cumpla, aunque no quede otorgado por ante escribano público ni testigos, sino con sola mi furma y que valga por codicillo mío o por v́ltima disposición y por la vía que de derecho pueda valer, y assí lo otorgo. Fecha en Valladolid en primero día del mes de diziembre de 1601 años.

Va testado donde dize que conuienen al des- y donde dize antes que amanezca- y va escrito en el margen -ál amanecer. Vala. Va testado donde dize -Señores. Entre ringlones -le supplico Vala. Testado mas le supplico. El doctor Eugenio de Salazar [Firma].

Iten, digo que en el dicho testamento cerrado que juntamente otorgamos la dicha mi muy amada muger y yo, declaró ella que se daba por contenta de su dote y arras con los negros que entonces teníamos, que son los nombrados en aquel testamento y les daba libertad dexando todos los demás bienes para la paga de mis deudas y acreedores -y porque las cosas no están oy en aquel estado, porque se han muerto dos negritos, y vna morena ${ }^{60}$ su hermana está tan enferma que no se tiene esperança de que aya de viuir-, y los morenos que quedan no satisfazen al valor de la dicha dote, que fueron mil y dozientos ducados poco más o menos y dozientos ducados de arras, y assí con los morenos solos que quedan, quedaría muy defraudada de su deuda, que es primera en tiempo y más priuilegiada en derecho; por tanto, mando que para en quenta de la dicha dote y arras, se le den los morenos que al tiempo de mi muerte estuuieren viuos, tasados justa y

58 Un espacio en blanco dentro del texto original, pero fácil de llenar (véase nota 49).

59 "que", tachado en el original.

60 "Ya murió esta morena", tercera nota autógrafa del autor, colocada al margen en el texto original. 
moderadamente conforme a los precios desta tierra, ${ }^{61}$ y sobre el valor dellos se le supla de lo más bien parado de mis bienes hasta la quantidad de los dichos mil y quatrocientos ducados de su dote y arras, que le son muy debidos. $Y$ de los demás bienes míos se pague lo que alcançare de mis deudas.

Y ruego a María de Figueroa y a María Carrillo que no dexen a su señora, pues veen que queda tan enferma y sola, sino que la acompafien y siruan como siempre lo han hecho, que demás de lo que en nuestro testamento ella y yo les mandamos dar, el señor las gratificará conforme al amor que las tiene [Rúbrica].

Memoria para nuestros albaseas, a quien supplico por amor de Dios la cumplan y no exhedan della, sin embargo de lo que en mi testamento dexo ordenado quanto a mi entierro [Rúbrica]. ${ }^{62}$

El doctor Eugenio de Salazar [Firma].

${ }^{61}$ En 1601, un año antes de la legalización de este codicilo, fue promulgada en España una ley que prohibía en Madrid la tenencia de esclavos, aunque en la práctica seguía habiéndolos, especialmente en el servicio doméstico (Kamen 85-89). Por el año de 1605, la saturación de esclavos negros en los mercados coloniales abarata la "mercancía de ébano". Sobre este asunto, Aguirre Beltrán agrega lo siguiente: "El precio de los negros comenz6 a descender en forma apreciable. Los esclavos que antes de la era de los grandes asientos llegaban a venderse en los puertos de entrada hasta a 500 pesos, eran para entonces vendidos en sólo 300 [...], según datos de los mismos factores eran vendidos a 300 pesos pieza de Indias, pues la saturación del mercado y poca demanda de los esclavos impedía el logro de un precio más elevado" (Aguirre Beltrán 44, 48 y 91).

62 El párrafo que se incluye al final debió ser, en realidad, la portadilla del documento original. Está escrito, en forma vertical, sobre el último pliego autógrafo. Es muy probable que este papel haya servido como cubierta del pequeño legajo, antes de la anexión del testamento al volumen de protocolos donde aparece integrado. 


\section{BIBLIOGRAFÍA CITADA}

AGCA: Archivo General de Centro América, Guatemala, Cd. AGI: Archivo General de Indias, Sevilla. AGNM: Archivo General de la Nación, México, D.F. Agutrre Beltrán, Gonzalo. La población negra de México. México: FCE, 1984.

Antonio, NicolÁs. Bibliotheca Hispana-Nova. 2 vols. Madrid: Joachimum de Ibarra, 1783-1788.

APM: Archivo de Protocolos de Madrid, Madrid.

Aut.: Real Academia Español.a. Diccionario de autoridades. Ed، facs.

3 vols. Madrid: Gredos, 1963.

Benttez, José R. Hisıoria gráfica de la Nueva España. México: Cámara oficial española de comercio en los Estados Unidos Mexicanos. 1929.

Blecua Perdices, José Manuel. "Notas para la historia de la novela en España." Serta Philológica F. Lázaro Carreter. Madrid: Cátedra. 1983.

Carbajo Isla, Maria F. La población de la villa de Madrid. Desde finales del siglo XVI hasta mediados del siglo XX. Madrid: Siglo XXI de España Editores. 1987.

Catálogo de pobladores 1941: Catálogo de pobladores de Nueva España. Ed. Edmundo O’Gorman. México: Archivo General de la Nación, 1941. CCS: Casa de Contratación de Indias, Sevilla.

Cioranescu, Alejandro. Ed. Eugenio de Salazar. Obras festivas. Santa

Cruz de Tenerife: Romerman Ediciones, 1968.

Cuevas, Mariano. Hisıoria de la Iglesia en México. 5 vols. El Paso Texas: Editorial Revista Católica, 1928.

Chaunu, Huguette et Pierre. Séville el l'Atlantique (1504-1650). 8 vols. Paris: École Pratique des Hautes Études, 1956.

DRAE: Diccionario de la Real Academia Española. Madrid: Real Academia Española, 1970.

EUIEA: Enciclopedia Universal Ilustrada Europeo-Americana. Madrid: Espasa-Calpe, 1966.

Dominguez Ortiz, Antonio. El Antiguo Régimen: los Reyes Católicos y los Austrias. Vol. 3. de IIistoria de España Alfaguara. 7 vols. Miguel Artola, dir. Madrid: Alfaguara / Alianza Editorial, 1973.

- Desde Carlos V a la Paz de los Pirineos (1517-1660). Barcelona: Grijalbo, 1974.

Dorantes de Carranza, Baltasar. Sumaria relación de las cosas de la Nueva España, con noticia individual de los descendientes legíti- 
mos de los conquistadores y primeros pobladores españoles. Ed. facs. Ed. José María de Ágreda y Sánchez. México: Jesús Medina Editor, 1970.

Fernández-Guerra y Orbe, Luis. Don Juan Ruiz de Alarcón y Mendoza. Extracto con nuevos documentos y datos. Ed. Alfonso Teja Zabre. México: Botas, 1939.

Garcfa de Palacios, Diego. Diálogos Militares Ed. facs. Ed. José María Mata Carriazo. Madrid: Ediciones Cultura Hispánica, 1964.

Guía 1987: Guía de las actas de Cabildo de la ciudad de México, siglo XVII (1601-1610). Ed. María Isabel Monroy Padilla et al. México: Departamento de Distrito Federal / Universidad Iberoamericana, 1987.

HAMLTON, EARL J. El tesoro americano y la revolución de los precios en España, 1501-1650. Trad. Ángel Abad. Barcelona: Ariel, 1975.

ICAZA, Francisco A. DE. Diccionario autobiográfico de conquistadores y pobladores de Nueva España. Ed. facs. 2 vols. Guadalajara, Jal.: Edmundo Aviña Levy Editor, 1969.

Kamen, Henry. Vocabulario básico de la Historia Moderna. España y América, 1450-1750. Barcelona: Crítica / Grijalbo, 1986.

KInG, Willard F. Juan Ruiz de Alarcón, letrado y dramaturgo. Su mundo mexicano y español. Trad. Antonio Alatorre. México: El Colegio de México, 1989.

León Pinelo, Antonio de. Epítome de la Biblioteca Oriental $i$ Ocridental, Náutica i Geográfica. Ed. facs. Ed. Agustín Millares Carlo. Washington, D.C.: Unión Panamericana, 1958.

LynCh, John. España bajo los Austrias. II. España y América (15981700). 2 vols. Barcelona: Ediciones Península, 1975.

Morales Padrón, Francisco. Cedulario de Canarias, 1576-1597. 3 vols. Sevilla: Excelentísimo Cabildo Insular de Gran Canaria / Escuela de Estudios Hispanoamericanos, 1970.

Navegación: Eugenio de SAlazAR, Nauegación del alma por el discurso de todas las edades del hombre. 1600. Biblioteca Nacional de Madrid. Ms. 3669, 79 fols.

Palau y Dulcet, Antonio. Manual del librero hispanoamericano. 28 vols. Barcelona: Librería Palau, 1966.

Paso y Troncoso, Francisco. Epistolario de Nueva España, 15051818. 14 vols. México: Antigua Librería Robredo de José Porrúa e hijos, 1940.

Pedroza, Francisco de. La Alusiriacha. Biblioteca Nacional de Madrid. Ms. 3960.

Pérez Pastor, Cristóbal. Bibliografía Madrileña. Descripción de las obras impresas en Madrid. 3 vols. Madrid: RABM, 1906-1907. 
Plaza y Jaén, Cristóbal de la. Crónicia de la Real y Pontificia Universidad de México. 2 vols. México: UNAM, 1931.

Porras Muñoz, Gullermo. El gobierno de la ciudad de México en el siglo XVI. México: UNAM, 1982.

Romeu Palazuelos, Enrique et al. Las Islas Canarias. Madrid: EspasaCalpe, 1981.

Salazar, Eugenio de. Cartas. Epistolario Español, vol. 2. Ed. Eugenio de Ochoa, Biblioteca de Autores Españoles 62. Madrid: Atlas, 1964, 283-310.

Salomón, Noel. La vida rural castellana en tiempos de Felipe II. Trad. Francesc Espinet Burunat. Barcelona: Planeta, 1973.

SchAfer, ERnesto. Las rúbricas del Consejo Real y Supremo de las Indias, desde la fundación del Consejo en 1524 hasta la.terminación del reinado de los Austrias. Sevilla: Universidad de Sevilla, 1934.

Silva: Eugenio de Salazar, Silua de poessía. Biblioteca de la Real Academia de la Historia de Madrid, Ms. C-56, 505 fols.

Zambrano, Francisco, S.J. Diccionario bio-bibliográfico de la Compañía de Jesús en México. 16 vols. México: Jus, 1965-1970. 